\title{
Impact of drug-eluting stents with different coating strategies on stent thrombosis: A meta-analysis of 19 randomized trials
}

\author{
Xiaowei $\mathrm{Niu}^{1}$, Cuiling Yang ${ }^{2}$, De Chen ${ }^{1}$, Shengliang $\mathrm{He}^{1}$, Dong $\mathrm{Yan}^{1}$, Yali Yao ${ }^{3}$ \\ ${ }^{1}$ Department of Cardiology, The First Clinical Medical College of Lanzhou University, Lanzhou, Gansu, China \\ ${ }^{2}$ Department of Infectious Diseases, The First Affiliated Hospital, School of Medicine, \\ Xi'an Jiaotong University, Xi'an, Shanxi, China \\ ${ }^{3}$ Department of Cardiology, The First Affiliated Hospital, Lanzhou University, Lanzhou, Gansu, China
}

\begin{abstract}
Background: Whether drug-eluting stents with biodegradable polymers (BP-DES) improve safety, especially with respect to stent thrombosis (ST) compared with permanent polymers DES $(P P-D E S)$, remains uncertain. We aimed to compare the short-and long-term outcomes and the $S T$ risk in patients treated with BP-DES vs. PP-DES.

Methods: We searched Medline, Embase, Web of science, CENTRAL databases, and conference proceedings/abstracts for randomized controlled trials (RCTS) comparing BP-DES with $P P-D E S$. The primary endpoint was to compare the risks of overall and different temporal categories of definite/probable ST. Other clinical outcomes were target lesion revascularization (TLR), myocardial infarction (MI), and all-cause death in short-term ( $\leq 1$ year) and long-term follow-up. The meta-analyses were performed by computing odds ratios (ORs) with 95\% confidence intervals (CIs) using a random-effects model.

Results: Nineteen RCTs including 20,229 patients were analyzed. Overall, BP-DES significantly decreased the risks of very late definite/probable ST (OR 0.33; 95\% CI 0.16-0.70), and TLR in long-term follow-up (OR 0.70; 95\% CI 0.52-0.95) compared with PP-DES. There were no significant differences between the groups regarding $M I$ incidence and mortality during both short and long follow-up periods. In stratified analyses, the long-term superiority of $B P-D E S$ was maintained only by using first-generation DES as the comparators.

Conclusions: The present meta-analysis indicated that BP-DES were more efficacious than $P P-D E S$ at reducing the risks of very late $S T$ and long-term TLR, but it could vary by heterogeneities in the use of PP-DES comparators. Additional rigorous RCTs with longer follow-up periods are warranted to verify these very promising long-term endpoints. (Cardiol J 2014; 21, 5: 557-568)
\end{abstract}

Key words: drug-eluting stents, biodegradable polymers, permanent polymers, stent thrombosis, meta-analysis

Address for correspondence: Yali Yao, MD, Department of Cardiology, The First Hospital of Lanzhou University, No. 1, Donggang West Road, Lanzhou, Gansu 730000, China, tel: +86-09318625200, fax: +86-931-8619797,

e-mail: yaoyalifs@163.com

Received: 11.11.2013 Accepted: 11.12.2013 


\section{Introduction}

Over the last decade, the introduction of drug-eluting stents (DES) has greatly changed the world of interventional cardiology [1]. First-generation DES with releasing antiproliferative agents from permanent polymer coatings have shown better performance in reducing the risk of restenosis and subsequent revascularization than bare metal stents [2], but at the expense of an increased occurrence of very late stent thrombosis (ST) [3, 4]. Incomplete endothelialization, delayed vessel healing and remodeling due to chronic inflammation within stented segment are likely to cause concerns for the DES $[5,6]$. The persistence of durable polymer coatings on DES might trigger the inflammation reaction after completed drugs elution $[5,7,8]$. To address the problem, different stent coating strategies have been developed [9] including biocompatible durable polymers, biodegradable polymers DES (BP-DES) and polymer-free DES. Second-generation DES are coated with a thinner permanent and biocompatible fluorocopolymer [1, 9]. Many trials have been conducted to indicate the lower rate of ST in patients treated with second-generation DES during long-term follow-up [10]. Nevertheless, the ongoing minimal inflammation process related to durable polymer materials is still under observation $[11,12]$.

Biodegradable polymer coatings on DES are regarded as a promising step forward in polymer technology [13]. BP-DES could provide a non-thrombogenic coating of exposed stent surfaces to decrease the risk of late complications [13-18]. Prior reports $[15,17]$ have revealed that biodegradation of the polymers within 6-9 months had promising long-term clinical results, especially regarding very late ST. In the latest SORT OUT V trial [19], however, it was found that the incidence of ST was $0.7 \%$ for biodegradable polymers based biolimus-eluting stents (Nobori) and $0.2 \%$ for permanent polymers sirolimus-eluting Cypher stents at both 9 and 12 months $(\mathrm{p}=0.034)$. Because of the low rates of ST [1], individual trials comparing BP-DES and permanent polymers-DES (PP-DES) were not appropriately powered to detect a statistically significant difference in the rates of adverse events [20]. We conducted a meta-analysis, which increases the statistical reliability by summarizing the results from all available trials, to investigate the short- and long-term effects and the ST rate of BP-DES compared with PP-DES in patients undergoing percutaneous coronary intervention (PCI).

\section{Methods}

\section{Selection criteria}

Eligibility criteria were: (1) randomized clinical trials (RCTs) comparing BP-DES with PP-DES in patients undergoing PCI; (2) studies reporting data on the outcomes of interest (reported below). Exclusion criteria were: (1) duplicated data; (2) sub-study of the RCT; (3) ongoing trials.

\section{Search strategy}

Studies were identified by searching electronic databases including Medline, Embase, Web of Science and the Cochrane Central Register of Controlled Trials (CENTRAL). This search was supplemented by scanning reference lists of eligible studies and relevant websites (www. clinicaltrialresults.org, www.tctmd.com, www.theheart.org, www.cardiosource.com, www.escardio. org). No limits were applied for language, date, or publication status. The following keywords and corresponding Medical Subject Headings were used: "bioresorbable", "bioabsorbable", "biodegradable", "drug-eluting stent", and "drug-coated stent". The last search was run on 8 June 2013.

\section{Study selection and data collection}

Two independent investigators (XWN, CLY) assessed reports for eligibility at title and/or abstract level, and then extracted data from shortlisted studies on pre-specified forms. Information included: (1) the trial's design, inclusion and exclusion criteria; (2) baseline patient and lesion characteristics; (3) features of the intervention and control arms; (4) clinical outcomes. In an attempt to overcome incomplete or selective data reporting, manuscripts that were presented at a meeting but had not yet been published in full-text form were included. As to missing or unclear information, we tried to contact original trial researchers by telephone or e-mail.

\section{Assessment of risk of bias in individual studies}

Two investigators independently (XWN, CLY) evaluated the internal validity of eligible trials in accordance with a set of 7 criteria of the Cochrane Handbook [21]: random sequence generation, allocation concealment, blinding of participants and personnel, blinding of outcome assessment, incomplete outcome data, selective outcome reporting, and other sources of bias (adequate description of 
sample size calculation and detailed disclosures of sources of funding). The judgements of bias were expressed as "Low risk", "High risk" or "Unclear risk". All divergences were resolved by consensus.

\section{Study outcomes and definitions}

The primary endpoints chosen for this meta-analysis were the cumulative rates of definite/probable ST as well as the occurrences of early/late (0 days to 1 year), very late (> 1 year) definite/probable ST. The secondary endpoints were ischemia-driven target lesion revascularization (TLR), myocardial infarction (MI), all-cause death. Endpoints occurred within 1 year follow-up time were defined as the short-term outcomes and those beyond 1 year as the long-term. Studies reporting only target vascular revascularization but not TLR data were excluded in TLR analyses.

The definitions of definite/probable ST and MI complied with the Academic Research Consortium (ARC) criteria [22]. TLR was defined as any percutaneous or surgical revascularization of the target lesion owing to symptoms or objective signs of ischemia as well as luminal renarrowing $\geq 50 \%$ detected by angiography at follow-up.

\section{Statistical analysis}

Two investigators (DC, YLY) examined data from all identified studies. When 2 or more RCTs were available for data pooling, meta-analyses were conducted for any outcome according to the intention-to-treat principle. Because of rare events and imbalance between groups, dichotomous outcomes were analyzed by computing pooled odds ratios (ORs) with 95\% confidence intervals (CIs) using the DerSimonian and Laird random-effects model [21]. Effect of treatment could not be assessed in trials when no events were reported in two arms. For trials in which no event occurred in one group, an automatic 'zero cell' correction was used in such groups [23]. Statistical heterogeneity was evaluated by the Cochrane $\mathrm{Q}$ test and the $\mathrm{I}^{2}$ statistic (with $\mathrm{p}$ values $<0.1$ and $\mathrm{I}^{2}$ values $>50 \%$ regarded as significant inconsistency) [21]. We used the funnel plot and Egger's tests to evaluate the presence of publication bias for the endpoints [21]. Sensitivity analyses were conducted to assess the consistency of primary outcomes, including different stent types and dual antiplatelet therapy duration (aspirin and thienopyridine). The treatment effects were examined by testing whether consecutively deleting each trial would change the overall treatment effect of the meta-analysis dramatically. All endpoints were evaluated in separate subgroup analyses according to the pre-specified stratified lengths of follow-up time. Results were statistically significant at two-sided $\mathrm{p}<0.05$. Statistical computations were performed with Review Manager 5.1 (the Cochrane Collaboration, Copenhagen, Denmark) and Stata 11.0 (College Station, Texas, USA).

\section{Results}

\section{Eligible studies}

From a total number of 836 potentially relevant publications, 19 RCTs with 27 studies met the inclusion criteria and were selected. Seventeen of these were full-text articles [19, 24-39] and 2 were meeting presentation [40, 41]. A flow diagram depicting the process of search strategy is shown in Figure 1, and main characteristics of the included studies are described in Table 1 . Among a total number of 20,229 patients that were enrolled, 11,134 were randomized to receive BP-DES, and 9,095 to PP-DES. Biodegradable polymer sirolimus-eluting stents (SES) was used in 9 trials (3,716 patients) and biolimus-eluting stents with a biodegradable polymer in 8 trials $(6,034$ patients). The remaining 2 trials used respectively everolimus and paclitaxel as drugs coated on BP-DES. With regard to the PP-DES arm, all the patients from the included studies were treated either with first-generation DES, SES (4,481 patients) and paclitaxel-eluting stents (1,003 patients), or with second-generation DES, everolimus-eluting stents (EES) (3,611 patients). The mean age of participants in individual trials ranged from 57 to 69 years with the majority of patients being male. The percentage of diabetes mellitus ranged from $15 \%$ to $60 \%$. Patients with acute MI were included in 8 trials [19, 25-27, 30, 32, 33, 38]. Recommended duration of dual antiplatelet therapy was at least 6 months in all trials except for 3 [38, $40,41]$. Follow-up ranged from 9 to 48 months and a weighted mean follow-up was 25.8 months. Some additional long-term follow-up information was retrieved from web-posted conference proceedings [42-44]. In terms of ST, only one trial did not adopt the ARC definition [35].

Table 2 lists the risk of bias among studies which were judged by 7 criteria [21]. All but 5 trials were described as randomization and allocation concealment adequate. Clinical endpoints were adjudicated in a blinded manner in 13 trials. All trials had a withdrawal of $<10 \%$ at the time of publication of the outcomes of interest in our analysis. Two meeting presentations [40, 41] are registered with ClinicalTrials.gov, number (NCT00825773, NCT00887211), which were not reported in the table. 


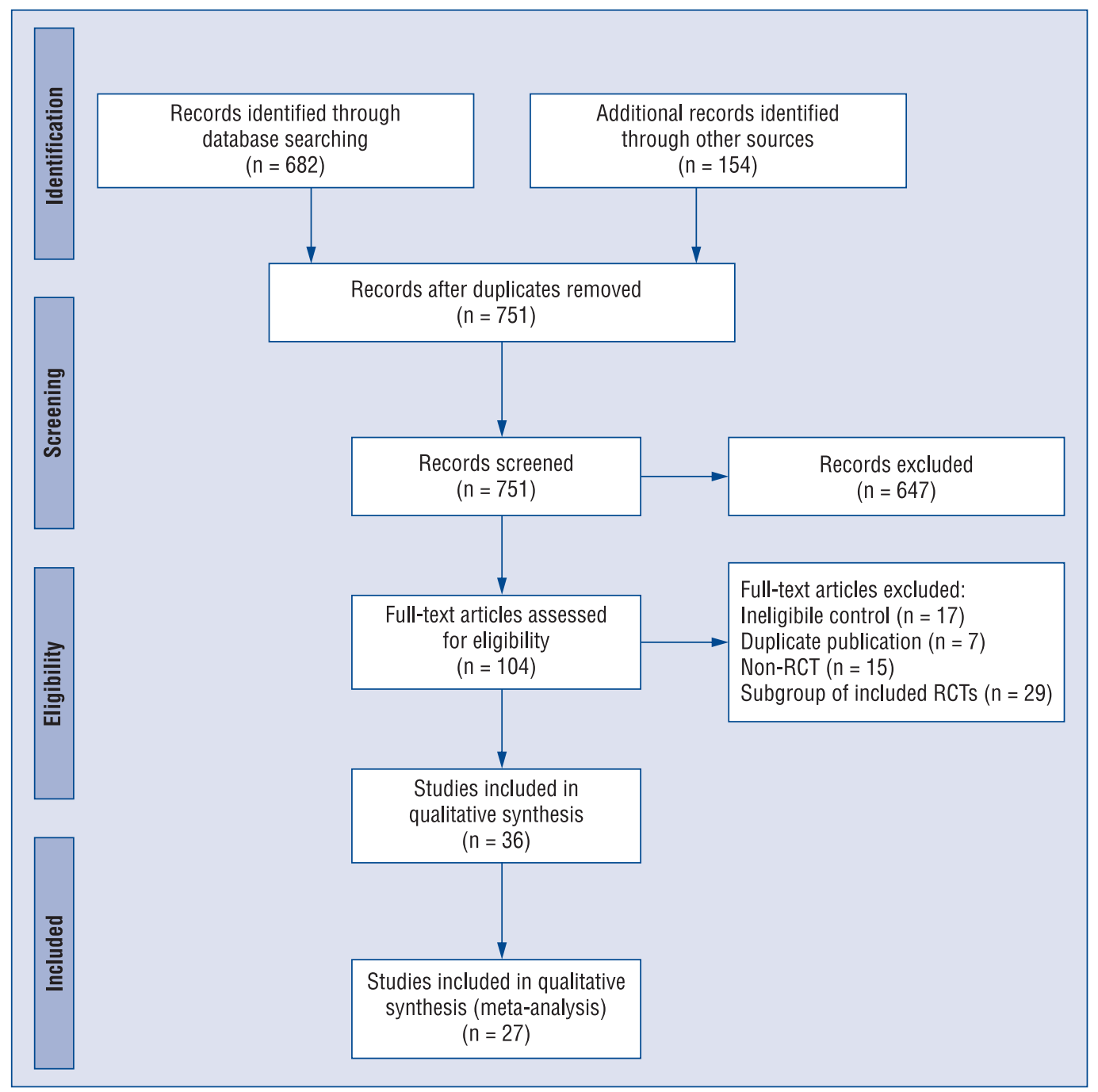

Figure 1. Flow diagram of the review process according to the PRISMA statement; RCT — randomized controlled trials.

\section{Meta-analysis}

Stent thrombosis. 18 RCTs including 18,529 patients reported the frequency of ARC definite or probable ST and were used for the quantitative analysis. Among the studied population, the incidence of overall ST was $0.78 \%$ (79 of 10,132) in the BP-DES and $1.10 \%(92$ of 8,397) in the PP-DES during the longest available follow-up period. In terms of the pooled risk of ST, no significant difference could be detected between BP-DES and PP-DES $\left(0.80 ; 0.58-1.10 ; \mathrm{p}\right.$ for effect $=0.17 ; \mathrm{I}^{2}=4 \%$; $\mathrm{p}$ for heterogeneity $=0.41$ ). A pre-specified stratified analysis for early/late and very late ST was evaluated. The rate of early/late ST was not different between two groups $(0.73 \%$ vs. $0.82 \%$; $0.92 ; 0.65-1.31 ; \mathrm{p}$ for effect $=0.66 ; \mathrm{I}^{2}=1 \%$; $\mathrm{p}$ for heterogeneity $=0.43$; Fig. 2 ). However, regarding the risk of very late ST, BP-DES use was associated with a nearly $70 \%$ reduction when compared with PP-DES $(0.3 \%$ vs. $0.9 \%$; $0.33 ; 0.16-0.70$; p for effect $=0.003 ; \mathrm{I}^{2}=0 \% ; \mathrm{p}$ for heterogeneity $=0.87$; Fig. 2).

Target lesion revascularization. $17 \mathrm{RCTs}$ including 17,890 patients contributed to the analysis of overall TLR. No significant difference regarding TLR was found with BP-DES vs. PP-DES in short-term follow-up (3.24\% vs. $3.80 \%$; 0.93 ; $0.73-1.19 ; \mathrm{p}$ for effect $=0.57 ; \mathrm{I}^{2}=31 \%$; $\mathrm{p}$ for heterogeneity $=0.12$; Fig. 3 ). However, in long-term follow-up, BP-DES use was associated with a significant reduction in the risk of TLR compared with PP-DES (8.42\% vs. $10.74 \%$; 0.70 ; 0.52-0.95; $\mathrm{p}$ for effect $=0.02 ; \mathrm{I}^{2}=38 \%$; $\mathrm{p}$ for heterogeneity $=0.12$; Fig. 3 ). 


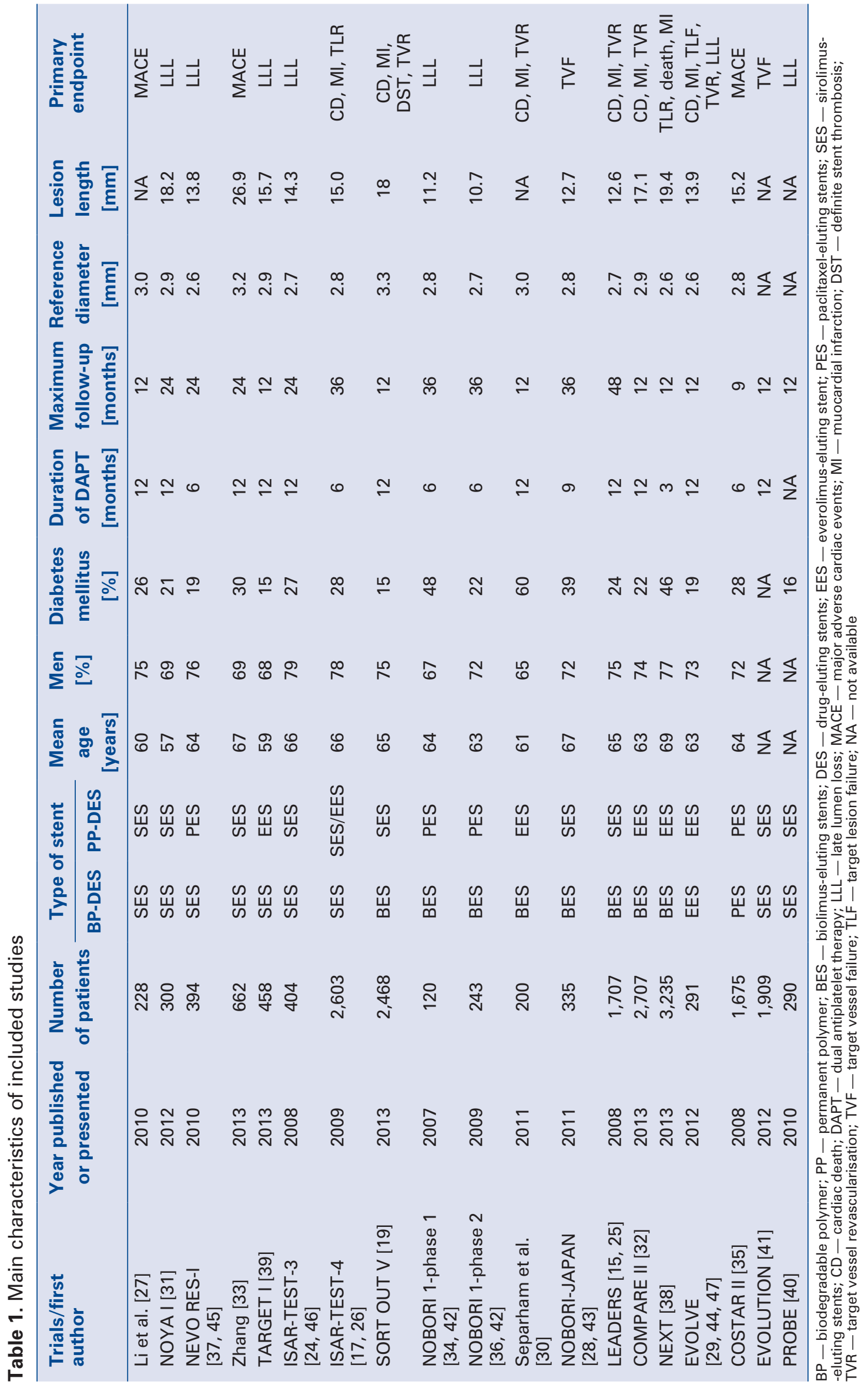


Table 2. Risk of bias table for included studies.

\begin{tabular}{|c|c|c|c|c|c|c|c|}
\hline Study & $\begin{array}{c}\text { Random } \\
\text { sequence } \\
\text { generation }\end{array}$ & $\begin{array}{l}\text { Allocation } \\
\text { concealment }\end{array}$ & $\begin{array}{l}\text { Blinding of } \\
\text { participants } \\
\text { and } \\
\text { personnel }\end{array}$ & $\begin{array}{l}\text { Blinding } \\
\text { of outcome } \\
\text { assessment }\end{array}$ & $\begin{array}{c}\text { Incomplete } \\
\text { outcome } \\
\text { data }\end{array}$ & $\begin{array}{l}\text { Selective } \\
\text { reporting }\end{array}$ & $\begin{array}{l}\text { Other } \\
\text { bias }\end{array}$ \\
\hline Li et al. & $A$ & B & B & B & $A$ & $A$ & B \\
\hline NOYA I & B & B & $A$ & $A$ & $A$ & $A$ & $A$ \\
\hline Zhang et al. & $A$ & $A$ & B & B & $A$ & $A$ & $A$ \\
\hline NEVO RES-I & $A$ & $A$ & $A$ & $A$ & $A$ & $A$ & $A$ \\
\hline TARGET I & $A$ & $A$ & $\mathrm{C}$ & $A$ & $A$ & $A$ & $A$ \\
\hline ISAR-TEST-3 & $A$ & $A$ & $A$ & $A$ & $A$ & $A$ & $A$ \\
\hline ISAR-TEST-4 & $A$ & $A$ & B & $A$ & $A$ & $A$ & $A$ \\
\hline SORT OUT V & $A$ & $A$ & B & $A$ & $A$ & $A$ & $A$ \\
\hline NOBORI 1-phase 1 & $A$ & $A$ & B & $A$ & $A$ & $A$ & $A$ \\
\hline NOBORI 1-phase 2 & $A$ & $A$ & B & $A$ & $A$ & $A$ & $A$ \\
\hline Separham et al. & B & B & B & B & B & $A$ & B \\
\hline NOBORI-JAPAN & B & B & B & $A$ & $A$ & $A$ & $A$ \\
\hline LEADERS & $A$ & $A$ & $A$ & $A$ & $A$ & $A$ & $A$ \\
\hline COMPARE II & $A$ & $A$ & C & $A$ & $A$ & $A$ & $A$ \\
\hline NEXT & $A$ & $A$ & B & $A$ & $A$ & $A$ & $A$ \\
\hline EVOLVE & $A$ & B & $A$ & $A$ & $A$ & $A$ & $A$ \\
\hline COSTAR II & $A$ & $A$ & $A$ & $A$ & $A$ & $A$ & $A$ \\
\hline
\end{tabular}

$\mathrm{A}$ - low risk; $\mathrm{B}$ - unclear risk; $\mathrm{C}$ - high risk

Myocardial infarction. $18 \mathrm{RCT}$ s including 19,632 patients contributed to the analysis of overall MI. The use of BP-DES vs. PP-DES resulted in similar risks of MI during both short follow-up period $(2.91 \%$ vs. $2.66 \% ; 1.13 ; 0.95$ -1.35 ; $\mathrm{p}$ for effect $=0.17$; $\mathrm{I}^{2}=0 \%$; $\mathrm{p}$ for heterogeneity $=0.78$; Fig. 4 ) and long follow-up period $(4.83 \%$ vs. $4.91 \%$; 0.98 ; $0.78-1.23$; p for effect $=0.85 ; \mathrm{I}^{2}=0 \% ; \mathrm{p}$ for heterogeneity $=0.81$; Fig. 4).

All-cause death. All-cause death was reported in 16 RCTs enrolling 17,723 patients. BP-DES and PP-DES use showed similar risks of death in both short-term follow-up $(2.21 \%$ vs. $2.41 \%$; 1.00 ; $0.82-1.23$; $\mathrm{p}$ for effect $=0.98 ; \mathrm{I}^{2}=0 \%$; $\mathrm{p}$ for heterogeneity $=0.94$; Fig. 5 ) and long-term follow-up $(6.73 \%$ vs. $7.56 \% ; 0.91 ; 0.75-1.10 ; \mathrm{p}$ for effect $=$ $=0.32 ; I^{2}=0 \% ; p$ for heterogeneity $=0.65 ;$ Fig. 5 ).

\section{Sensitivity and influence analysis}

Stratified analyses were performed to evaluate the consistency of our findings (Table 3A, B). The short-term effect of treatment (BP-DES) on each endpoint was maintained by using $\leq 6$ - or 12-month duration of dual antiplatelet therapy, different DES types. The beneficial long-term tre- atment effect of BP-DES, however, was supported by using first-generation DES as the comparators and 12-month clopidogrel use. The analyses for the BP-DES subtypes (biolimus, sirolimus, paclitaxel or everolimus) found: (1) a significantly lower risk of long-term TLR was associated with the use of all types of BP-DES but paclitaxel-eluting stents compared with PP-DES; (2) biolimus-eluting stents reduced the risk of very late ST in comparison with PP-DES.

Because we included 2 RCTs $[40,41]$ only with meeting presentations in the present analysis, we repeated all analyses using full-length articles alone. The treatment effects for each outcome were consistent with our overall findings. Additionally, influence analysis demonstrated that no single study obviously changed the pooled ORs for ST, TLR, MI, or death.

\section{Publication bias}

Visual inspection of the funnel plot for ST did not reveal an apparent asymmetry (Fig. 6) with the support of the Egger's test $(\mathrm{p}=0.25)$. Similar results were found for TLR (Egger's test $p=0.20$ ), MI (Egger's test $\mathrm{p}=0.29$ ), and all-cause death $($ Egger's test $\mathrm{p}=0.64)$. 


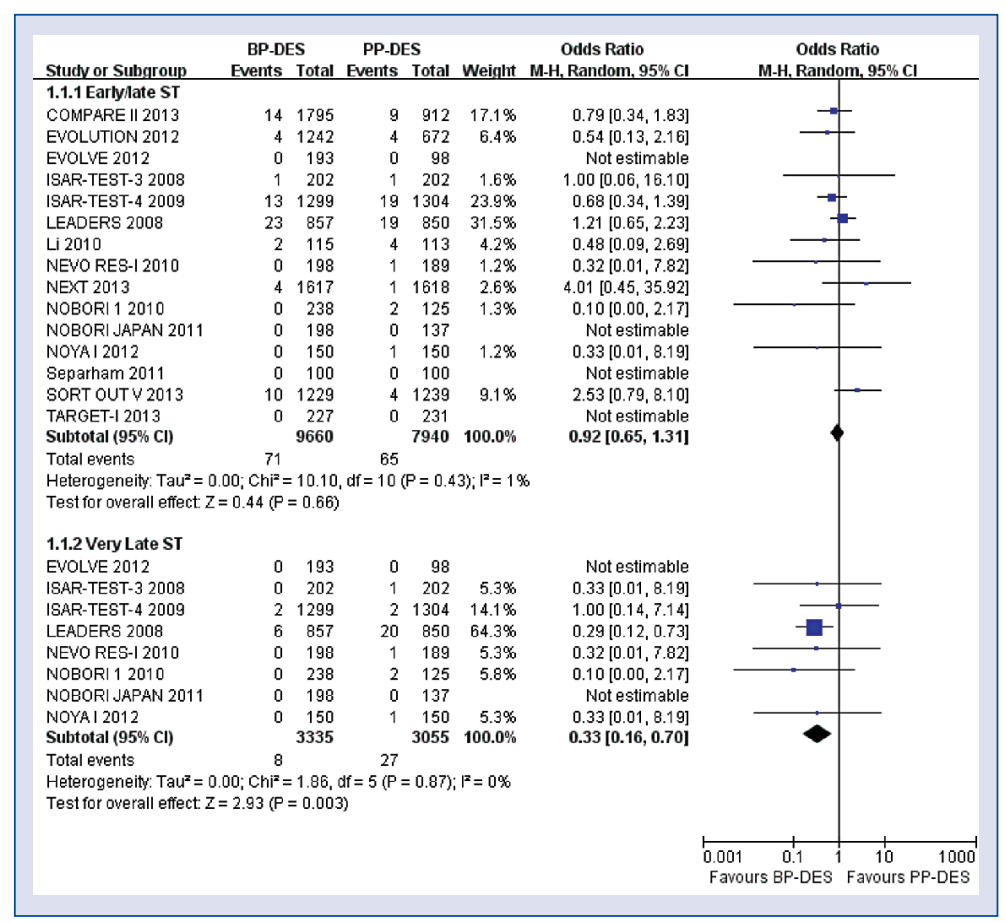

Figure 2. Forest plot for stent thrombosis (ST) in patients treated with biodegradable polymer drug-eluting stents (BP-DES) vs. permanent polymer drug-eluting stents (PP-DES) according to prespecified subgroup analyses: (1) early ST/ /late ST; (2) very late ST. BP-DES use was associated with a reduction in the risk of very late ST when compared with PP-DES; M-H - Mantel-Haenszel; $\mathrm{Cl}$ - confidence interval.

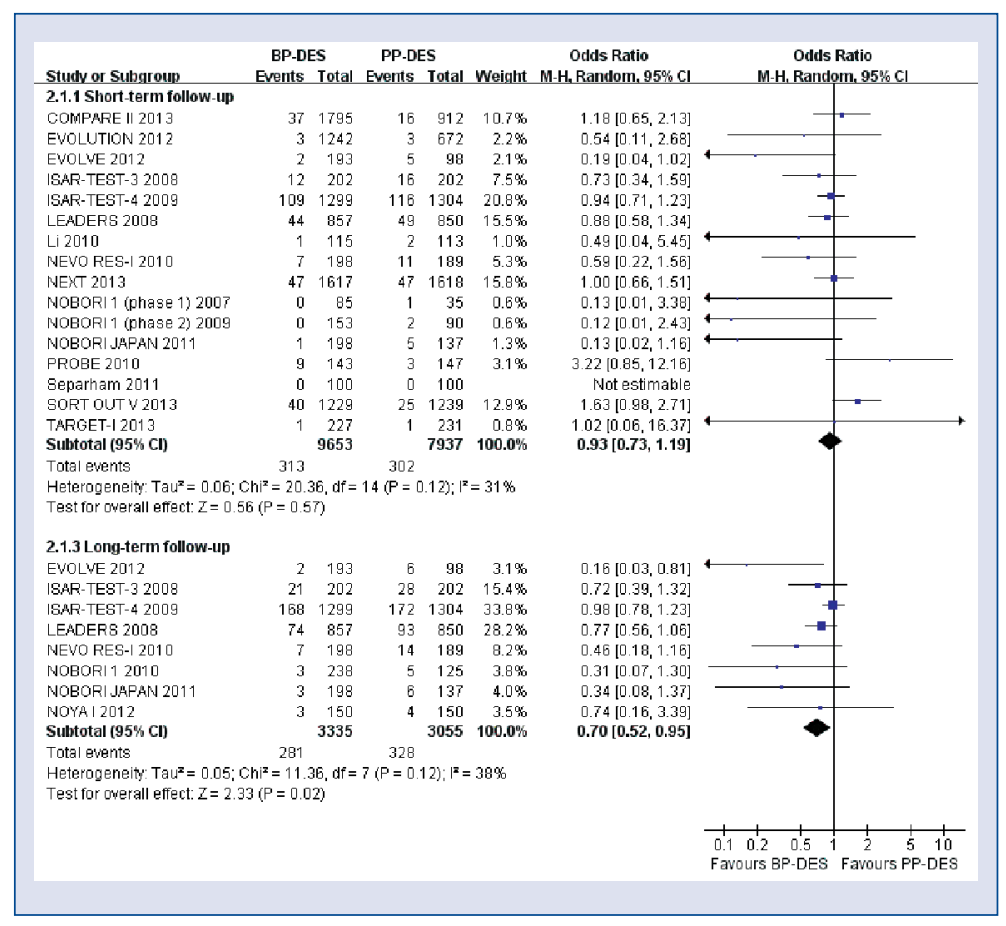

Figure 3. Forest plot with odds ratios for target lesion revascularization (TLR) associated with biodegradable polymer drug-eluting stents (BP-DES) vs. permanent polymer drug-eluting stents (PP-DES) in short- and long-term follow-up. BP-DES use was associated with a reduction in the risk of TLR in long-term follow-up when compared with PP-DES; $\mathrm{M}-\mathrm{H}$ - Mantel-Haenszel; $\mathrm{Cl}$ - confidence interval. 


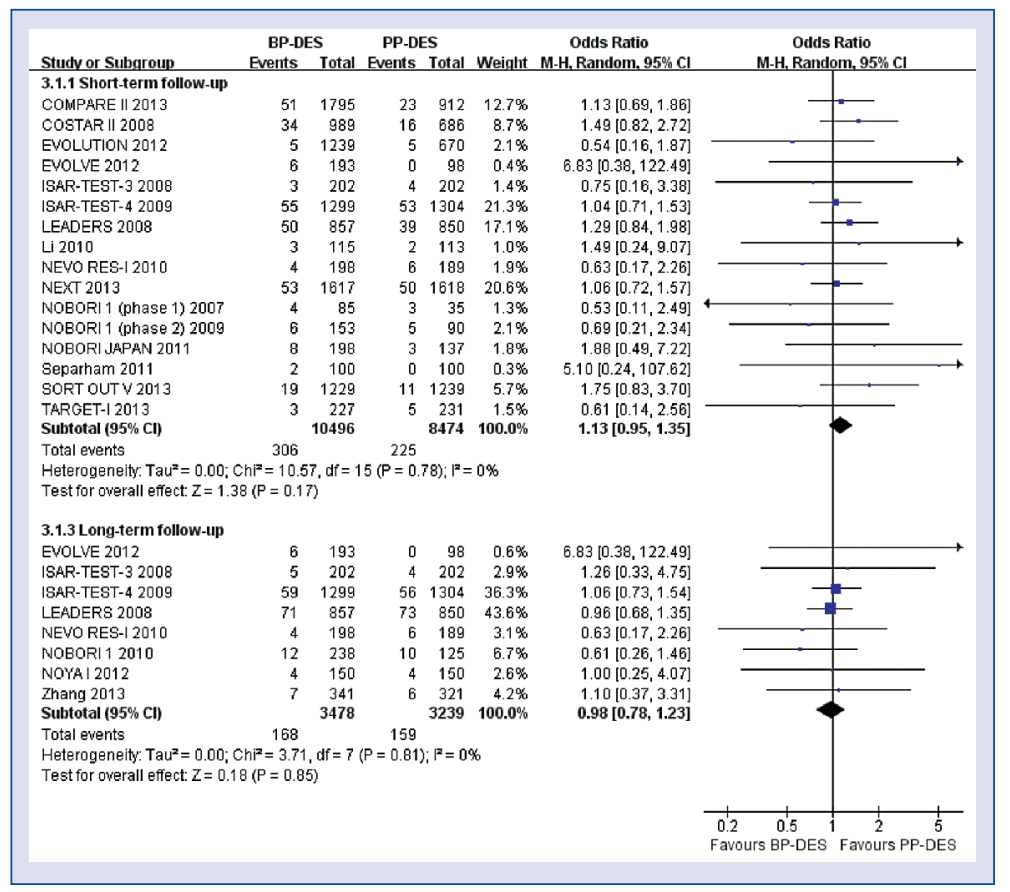

Figure 4. Forest plot with odds ratios for myocardial infarction (MI) associated with biodegradable polymer drug-eluting stents (BP-DES) vs. permanent polymer drug-eluting stents (PP-DES) in short- and long-term follow-up. The use of BP-DES vs. PP-DES resulted in similar risks of MI during both short and long follow-up period; $\mathrm{M}-\mathrm{H}-\mathrm{Mantel-}$ -Haenszel; $\mathrm{Cl}$ - confidence interval.

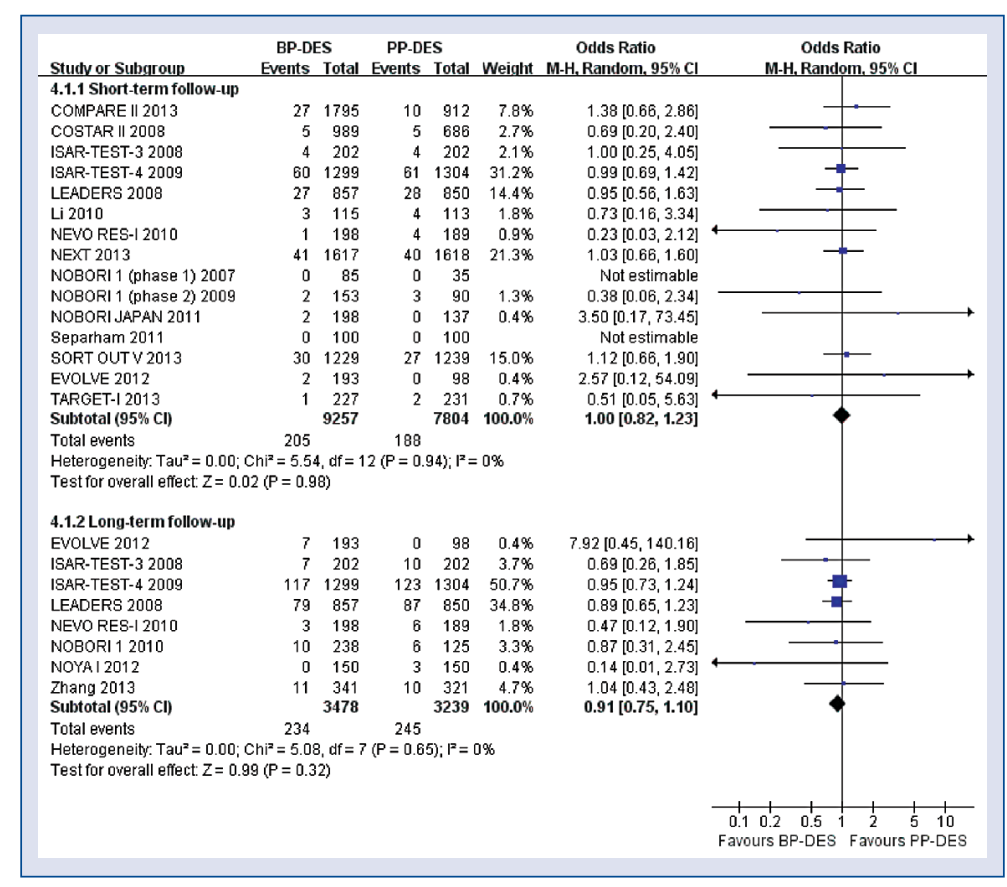

Figure 5. Forest plot with odds ratios for death associated with biodegradable polymer drug-eluting stents (BP-DES) vs. permanent polymer drug-eluting stents (PP-DES) in short- and long-term follow-up. The use of BP-DES vs. PP-DES resulted in similar risks of all-cause death during both short and long follow-up period; M-H - Mantel-Haenszel; $\mathrm{Cl}$ - confidence interval. 
Table 3. Stratified analyses of included studies.

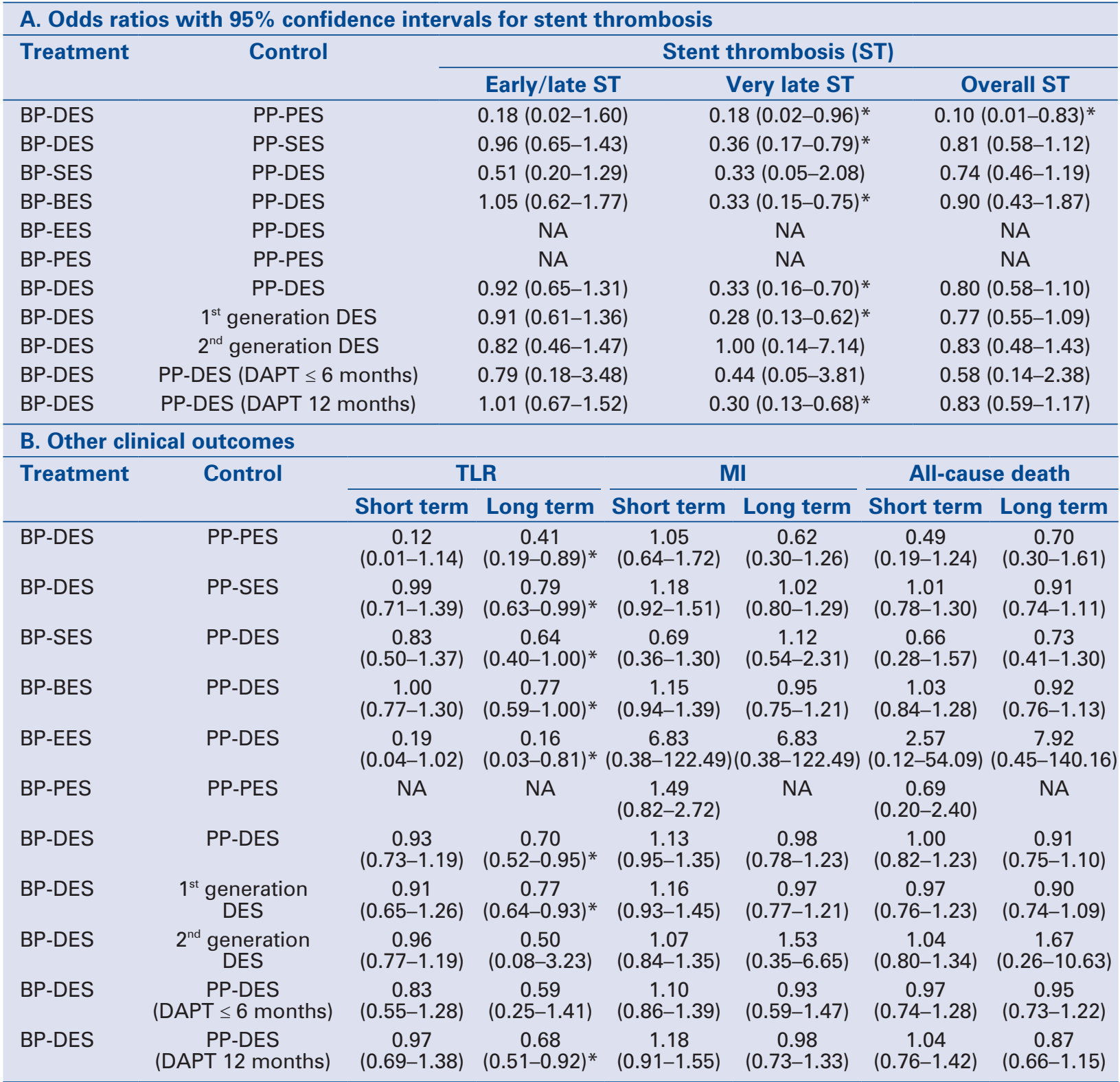

*Significant comparisons; The pooled estimates are reported as odds ratio (95\% confidence interval); BP — biodegradable polymer; PP - permanent polymer; BES - biolimus-eluting stents; DES - drug-eluting stents; EES — everolimus-eluting stent; PES - paclitaxel-eluting stents; SES - sirolimus-eluting stents; DAPT — dual antiplatelet therapy; NA — not applicable

\section{Discussion}

\section{Overall findings}

In this meta-analysis with 20,229 patients enrolled in 19 randomized trials, main findings could be summarized as follows: (1) BP-DES were associated with decreased risks of definite or probable very late ST and long-term TLR compared with PP-DES, however, the long-term superiority of BP-DES was only maintained by using first-generation DES as the comparators in stratified analyses. (2) BP-DES had similar rates of definite or probable ST and TLR to PP-DES during the short follow- -up period. (3) No significant difference was found regarding efficacy and safety between BP-DES and current standard second-generation DES using biocompatible permanent polymer. (4) Both groups had the comparable rates of MI and all-cause death in the short- and long-term follow-up.

\section{Possible mechanisms of benefit}

Although differences in DES system performances may be attributed to any of its 3 components, namely a metallic stent platform, an antiproliferative agent, and a coating polymer [1], some changes in coating strategies may account 


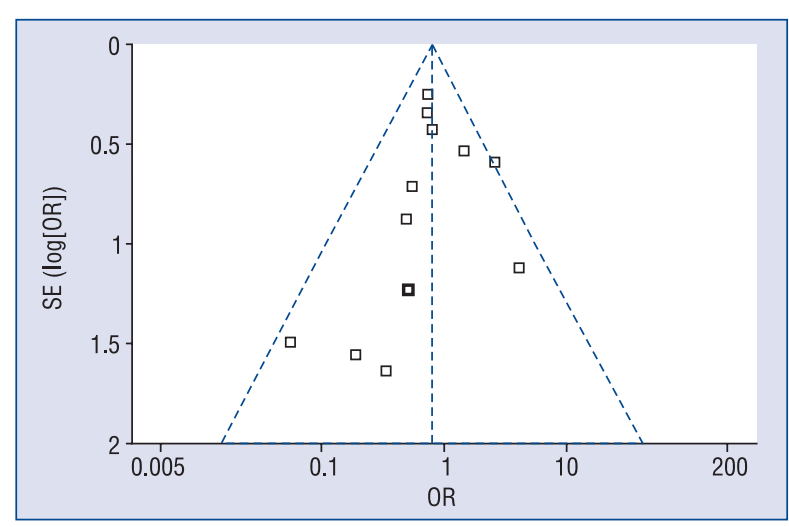

Figure 6. Funnel plot comparing standard error (SE) and odds ratio (OR) for stent thrombosis.

for these results. Based on lots of animal experiments and studies in DES-treated human subjects, researchers have demonstrated that very late ST may be caused by incomplete re-endothelialization, delayed arterial healing and remodeling due to the ongoing stented vessel wall inflammation $[5,6]$. The etiology of the chronic inflammatory response is multifactorial such as lesion characteristics and patient-, device-, and procedural-related factors, however, the persistence of permanent polymer coatings which eluted antiproliferative drugs was likely a primary inflammatory stimulus $[5,7,8]$. Development of biodegradable polymers on DES meant that the stent would be polymer-free and drug-free like a bare-metal stent after polymer absorption, thereby eliminating the long-term sequelae of durable polymer residue [13, 15, 16]. An optical coherence tomography study [18] showed earlier endothelialization associated with BP-DES vs. PP-DES within 9 months after implantation, indicating an improved vascular chronic inflammation. Hamilos et al. [14] also found better preserved endothelium-dependent vasomotion of BP-DES than that of permanent polymer-coated SES.

Besides biodegradable polymers on DES, the biocompatible fluoropolymers used in the second-generation DES were associated with less thrombogenicity [10]. Although BP-DES offered a theoretical advantage over DES with durable biocompatible polymers $[11,12,32,48]$, our study failed to demonstrate this benefit. This finding implied that the variability in BP-DES efficacy and safety across control DES reflected a real attenuation of treatment effects. Two recent large meta-analyses [10, 49] have clearly demonstrated that second-generation SES reduced the relative risk of early ST, late ST, cumulative 1-year ST, and very late ST compared with other DES (paclitaxel-, sirolimus-, and zotarolimus-eluting stents). Based on these excellent outcomes, it will be difficult to see any significant differences between BP-DES and EES. In a registry [48] including 814 patients with a median follow-up of 22 months, biolimus-eluting stents were similar to EES regarding safety (ST, MI or death) or efficacy (target vessel revascularization). In future clinical trials, more second-generation DES should be considered competitive comparators to corroborate the present finding.

Additionally, when the clinical follow-up period was extended ( $>1$ year), the improvement in clinical restenosis (TLR) was maintained in patients treated with BP-DES. This finding was potentially associated with the reduction of the inflammation burden and late catch-up restenosis after implantation of BP-DES [15]. Taken together, both minimization of the risk of very late ST and the long-term potent anti-restenosis effects in part reflected the accelerated re-endothelialization and improved coronary artery healing with BP-DES use.

\section{DES comparisons}

Although the results of our stratified analysis showed a consistent short-term effect of treatment among different BP-DES types, we did detect differences in the rates of very late ST and long-term TLR. The potential clinical benefit of BP-DES was thought to fully grow only during the late phase after stent intervention, when the polymer coatings already degraded and antiproliferative dugs completely eluted leaving the stent surface more close to bare-metal scaffolds. Therefore, the influence of the polymers and active drugs composing DES on long-term clinical outcomes seemed negligible, while bare-metal scaffolds may be dominant factors of long-term effects $[13,15,33,50]$. In fact, meaningful differences regarding ST in head-to-head trials of bare-metal stents have not been reported [50]. In theory, the property of BP-DES might allow shorter duration of dual antiplatelet therapy. However, the beneficial long-term treatment effect of BP-DES was only maintained by using 12 -month duration of dual antiplatelet therapy regimens. This might be due to the fact that the complete degradation of most used polymers needed nearly a year [15]. The selection of short-term dual antiplatelet therapy would need to be reconsidered in patients treated with BP-DES. Finally, the estimates variation was due in part to the subdivision of data into several smaller subgroups [51]. 


\section{Implications of the present study}

Firstly, very late ST, which is a rare event but more prevalent in higher-risk patients and lesions, turned into catastrophic outcomes after 1-year of stents' implantation [22]. In this setting, our meta-analysis had the clinical importance, which revealed a performance difference for very late definite or probable ST between BP-DES and PP-DES use. Secondly, BP-DES have combined the low restenosis rate with the enhanced long-term safety profile. It also supported the earlier evidence that the presence of residual durable polymers in DES initiated a persisting inflammatory reaction, which not only promoted thrombogenity of the device but also potentially increased neointimal hyperplasia within the stented segment $[5,7,8]$. Moreover, the benefit of BP-DES was at least non-inferior to EES, which were regarded as a gold standard to which new stent designs should be compared [32]. The finding provided a justification for trials further evaluating safety of the biodegradable polymer stent design in the long-term follow-up.

\section{Limitations of the study}

We cannot deny that our study has several limitations. Firstly, as this meta-analysis is not based on patient-level data, it shares the possible shortcomings of the original articles. Moreover, we could not conduct subset analyses of patients with diabetics, complex lesions, or MI. Secondly, we are unable to extend our findings to other second-generation DES (zotarolimus-eluting stents). Thirdly, the long-term superiority of BP-DES is only against first-generation DES, which are not used in daily clinical practice. Finally, the selection criteria for DES with different coating strategies should have a comprehensive assessment of the overall devices performance rather than taking into consideration only thrombosis susceptibility. Notwithstanding these limitations, studies using the uniform and standardized definition of ST were included in the meta-analysis to decrease the risk of bias. As only RCTs were included, our point estimates for all outcomes were less likely influenced by confounding bias.

\section{Conclusions}

The present meta-analysis showed that BP-DES were more efficacious than PP-DES at reducing the risks of very late definite/probable ST and long-term TLR, but it could vary by heterogeneities in the use of PP-DES comparators. No significant differences regarding safety and efficacy outcomes within short follow-up period were observed. RCTs with longer follow-up are warranted to verify these very promising long-term endpoints.

Conflict of interest: We declare that we have no financial, consultant, institutional and personal relationships with other people or organizations that can inappropriately influence our work and lead to bias or a conflict of interest.

\section{References}

1. Stefanini GG, Holmes DR Jr. Drug-eluting coronary-artery stents. N Engl J Med, 2013; 368: 254-265.

2. Kirtane AJ, Gupta A, Iyengar S et al. Safety and efficacy of drug-eluting and bare metal stents: comprehensive meta-analysis of randomized trials and observational studies. Circulation, 2009; 119: 3198-3206.

3. Kastrati A, Mehilli J, Pache J et al. Analysis of 14 trials comparing sirolimus-eluting stents with bare-metal stents. N Engl J Med, 2007; 356: 1030-1039.

4. Kimura T, Morimoto T, Nakagawa Y et al. Very late stent thrombosis and late target lesion revascularization after sirolimus-eluting stent implantation: five-year outcome of the j-Cypher Registry. Circulation, 2012; 125: 584-591.

5. Joner M, Finn AV, Farb A et al. Pathology of drug-eluting stents in humans: delayed healing and late thrombotic risk. J Am Coll Cardiol, 2006; 48: 193-202.

6. Luscher TF, Steffel J, Eberli FR et al. Drug-eluting stent and coronary thrombosis: biological mechanisms and clinical implications. Circulation, 2007; 115: 1051-1058.

7. Byrne RA, Joner M, Kastrati A. Polymer coatings and delayed arterial healing following drug-eluting stent implantation. Minerva Cardioangiol, 2009; 57: 567-584.

8. Finn AV, Nakazawa G, Joner $M$ et al. Vascular responses to drug eluting stents: Importance of delayed healing. Arterioscler Thromb Vasc Biol, 2007; 27: 1500-1510.

9. Jukema JW, Ahmed TA, Verschuren JJ, Quax PH. Restenosis after PCI. Part 2: Prevention and therapy. Nat Rev Cardiol, 2012; 9: 79-90.

10. Palmerini T, Biondi-Zoccai G, Della Riva D et al. Stent thrombosis with drug-eluting and bare-metal stents: evidence from a comprehensive network meta-analysis. Lancet, 2012; 379: 1393-1402.

11. Nakazawa G, Vorpahl M, Finn AV, Narula J, Virmani R. One step forward and two steps back with drug-eluting-stents: from preventing restenosis to causing late thrombosis and nouveau atherosclerosis. J Am Coll Cardiol Cardiovasc Imaging, 2009; 2: 625-628.

12. Kandzari DE, Leon MB, Popma JJ et al. Comparison of zotarolimus-eluting and sirolimus-eluting stents in patients with native coronary artery disease: A randomized controlled trial. J Am Coll Cardiol, 2006; 48: 2440-2447.

13. Byrne RA, Kastrati A. No country for old stents? Improving long-term patient outcomes with biodegradable polymer drug-eluting stents. Expert Rev Cardiovasc Ther, 2012; 10: 429-432.

14. Hamilos MI, Ostojic M, Beleslin B et al. Differential effects of drug-eluting stents on local endothelium-dependent coronary vasomotion. J Am Coll Cardiol, 2008; 51: 2123-2129. 
15. Stefanini GG, Kalesan B, Serruys PW et al. Long-term clinical outcomes of biodegradable polymer biolimus-eluting stents versus durable polymer sirolimus-eluting stents in patients with coronary artery disease (LEADERS): 4 year follow-up of a randomised non-inferiority trial. Lancet, 2011; 378: 1940-1948.

16. Koppara T, Joner M, Bayer G et al. Histopathological comparison of biodegradable polymer and permanent polymer based sirolimus eluting stents in a porcine model of coronary stent implantation. Thromb Haemost, 2012; 107: 1161-1171.

17. Byrne RA, Kastrati A, Massberg S et al. Biodegradable polymer versus permanent polymer drug-eluting stents and everolimusversus sirolimus-eluting stents in patients with coronary artery disease: 3-year outcomes from a randomized clinical trial. J Am Coll Cardiol, 2011; 58: 1325-1331.

18. Barlis P, Regar E, Serruys PW et al. An optical coherence tomography study of a biodegradable vs. durable polymer-coated limus-eluting stent: A LEADERS trial sub-study. Eur Heart J, 2010; 31: 165-176.

19. Christiansen EH, Jensen LO, Thayssen P et al. Biolimus-eluting biodegradable polymer-coated stent versus durable polymer-coated sirolimus-eluting stent in unselected patients receiving percutaneous coronary intervention (SORT OUT V): A randomised non-inferiority trial. Lancet, 2013; 381: 661-669.

20. Kastrati A, Neumann FJ. SORT OUT V: A new episode in the DES wars. Lancet, 2013; 381: 609-611.

21. Higgins JPT, Green S. Cochrane handbook for systematic reviews of Interventions Version 5.1. 0. Updated March 2011. The Cochrane Collaboration. 2011. Available from www.cochrane-handbook.org.

22. Cutlip DE, Windecker S, Mehran R et al. Clinical end points in coronary stent trials: A case for standardized definitions. Circulation, 2007; 115: 2344-2351.

23. Cassese S, Ndrepepa G, King LA et al. Two zotarolimus-eluting stent generations: a meta-analysis of 12 randomised trials versus other limus-eluting stents and an adjusted indirect comparison. Heart, 2012; 98: 1632-1640.

24. Mehilli J, Byrne RA, Wieczorek A et al. Randomized trial of three rapamycin-eluting stents with different coating strategies for the reduction of coronary restenosis. Eur Heart J, 2008; 29: 1975-1982.

25. Windecker S, Serruys PW, Wandel S et al. Biolimus-eluting stent with biodegradable polymer versus sirolimus-eluting stent with durable polymer for coronary revascularisation (LEADERS): A randomised non-inferiority trial. Lancet, 2008; 372: 1163-1173.

26. Byrne RA, Kastrati A, Kufner S et al. Randomized, non-inferiority trial of three limus agent-eluting stents with different polymer coatings: The Intracoronary Stenting and Angiographic Results: Test Efficacy of 3 Limus-Eluting Stents (ISAR-TEST-4) Trial. Eur Heart J, 2009; 30: 2441-2449.

27. Li Q, Wang LF, Yang XC et al. Efficacy comparison of primary percutaneous coronary intervention with biodegradable polymer- and durable polymer-based sirolimus-eluting stents for patients with acute myocardial infarction. Zhonghua xin xue guan bing za zhi, 2010; 38: 886-890.

28. Kadota K, Muramatsu T, Iwabuchi M et al. Randomized comparison of the Nobori Biolimus A9-eluting stent with the sirolimus-eluting stent in patients with stenosis in native coronary arteries. Catheter Cardiovasc Interv, 2012; 80: 789-796.

29. Meredith IT, Verheye S, Dubois CL et al. Primary endpoint results of the EVOLVE trial: A randomized evaluation of a novel bioabsorbable polymer-coated, everolimus-eluting coronary stent. J Am Coll Cardiol, 2012; 59: 1362-1370.

30. Separham A, Sohrabi B, Aslanabadir N et al. The twelve-month outcome of biolimus eluting stent with biodegradable polymer compared with an everolimus eluting stent with durable polymer. J Cardiovasc Thoracic Res, 2011; 3: 113-116.

31. Xu B, Dou K, Yang Y, et al. Nine-month angiographic and 2-year clinical follow-up of the NOYA biodegradable polymer sirolimus-eluting stent in the treatment of patients with de novo native coronary artery lesions: The NOYA I trial. EuroIntervention, 2012; 8: 796-802.

32. Smits PC, Hofma S, Togni M et al. Abluminal biodegradable polymer biolimus-eluting stent versus durable polymer everolimus-eluting stent (COMPARE II): A randomised, controlled, non-inferiority trial. Lancet, 2013; 381: 651-660.

33. Zhang Y, Shen J, Li Z et al. Two-year clinical outcomes of different drug-eluting stents with different polymer coating strategies in coronary artery heart disease: A multi-centre, randomised, controlled clinical trial. Int J Cardiol, 2013; 168: 2646-2652.
34. Chevalier B, Serruys PW, Silber S et al. Randomised comparison of Nobori, biolimus A9-eluting coronary stent with a Taxus(R), paclitaxel-eluting coronary stent in patients with stenosis in native coronary arteries: The Nobori 1 trial. EuroIntervention, 2007; 2: 426-434.

35. Krucoff MW, Kereiakes DJ, Petersen JL et al. A novel bioresorbable polymer paclitaxel-eluting stent for the treatment of single and multivessel coronary disease: Primary results of the COSTAR (Cobalt Chromium Stent With Antiproliferative for Restenosis) II study. J Am Coll Cardiol, 2008; 51: 1543-1552.

36. Chevalier B, Silber S, Park SJ et al. Randomized comparison of the nobori biolimus A9- eluting coronary stent with the taxus liberte paclitaxel-eluting coronary stent in patients with stenosis in native coronary arteries: The NOBORI 1 trial-phase 2. Circ Cardiovasc Interv, 2009; 2: 188-195.

37. Ormiston JA, Abizaid A, Spertus J et al. Six-month results of the NEVO Res-Elution I (NEVO RES-I) trial: A randomized, multicenter comparison of the NEVO sirolimus-eluting coronary stent with the TAXUS Liberte paclitaxel-eluting stent in de novo native coronary artery lesions. Circ Cardiovasc Interv, 2010; 3: 556-564.

38. Natsuaki M, Kozuma K, Morimoto T et al. Biodegradable Polymer Biolimus-eluting Stent versus Durable Polymer Everolimus-eluting Stent: A randomized, controlled, non-inferiority trial. J Am Coll Cardiol, 2013; 62: 181-190.

39. Gao RL, Xu B, Lansky AJ et al. A randomised comparison of a novel abluminal groove-filled biodegradable polymer sirolimus-eluting stent with a durable polymer everolimus-eluting stent: Clinical and angiographic follow-up of the TARGET I trial. EuroIntervention, 2013; 9: 75-83.

40. Gao RL, Xu B, Yang Y et al. A prospective multicenter randomized trial of PROSTENT bioabsorbable polymer vs. FIREBIRD durable polymer sirolimus-eluting stent: 9-month angiographic and 12-month clinical results. J Am Coll Cardiol, 2010; 56: B55.

41. Ge J. Sirolimus-eluting stent with biodegradable-polymer versus sirolius-eluting stent with durable polymer for the treatment of patients with de novo coronary artery lesions (EVOLUTION): A randomised non-inferiority trial. Presented at: EuroPCR 2012; May 17.

42. Chevalier B, Serruys PWJC, Silber S et al. Nobori 1: Long term results: 3 years phase 1 and 2 and 4 years phase 1 . EuroIntervention, 2010; 6 (Suppl. H): 39.

43. Kimura T, Muramatsu T, Iwabuchi M et al. Three year follow up of a randomized comparison of NOBORI, Biolimus A9 eluting stent (BES) with CYPHER, Sirolimus eluting stent (SES) for coronary revascularization in Japanese population. J Am Coll Cardiol, 2012; 60: B182.

44. Meredith IT, Verheye S, Dubois CL et al. Six-month IVUS and 12 -month clinical outcomes in the EVOLVE FHU trial: a randomised evaluation of a novel bioabsorbable polymer-coated, everolimus-eluting stent. EuroIntervention, 2012; 8 (Suppl. N): 42.

45. Abizaid A, Ormiston JA, Fajadet J et al. Two-year follow-up of the NEVO RES-ELUTION I (NEVO RES-I) trial: A randomised, multicentre comparison of the NEVO sirolimus-eluting coronary stent with the TAXUS Liberte paclitaxel-eluting stent in de novo native coronary artery lesions. EuroIntervention, 2013; 9: 721-729.

46. Byrne RA, Kufner S, Tiroch K et al. Randomised trial of three rapamycin-eluting stents with different coating strategies for the reduction of coronary restenosis: 2-year follow-up results. Heart, 2009; 95: 1489-1494.

47. Meredith IT, Verheye S, Weissman NJ et al. Six-month IVUS and two-year clinical outcomes in the EVOLVE FHU trial A randomised evaluation of a novel bioabsorbable polymer-coated, everolimus-eluting stent. EuroIntervention, 2013; 9: 308-315.

48. Puricel S, Oberhansli M, Guntern P et al. Long-term comparison of everolimus-eluting and biolimus-eluting stents. EuroIntervention, 2013; 9: 336-344.

49. Palmerini T, Kirtane AJ, Serruys PW et al. Stent thrombosis with everolimus-eluting stents: Meta-analysis of comparative randomized controlled trials. Circ Cardiovasc Interv, 2012; 5: 357-364.

50. Kolandaivelu K, Swaminathan R, Gibson WJ et al. Stent thrombogenicity early in high-risk interventional settings is driven by stent design and deployment and protected by polymer-drug coatings. Circulation, 2011; 123: 1400-1409.

51. Navarese E P, Koziński M, Pafundi T et al. Practical and updated guidelines on performing meta-analyses of non-randomized studies in interventional cardiology. Cardiol J, 2011; 18: 103-109. 